\title{
A retrospective study of the Antibiotics Prophylactic Use in Appendectomy Patient with ATC/DDD and DU 90\% Method in Regional General Hospital in Jakarta
}

\author{
Azrifitria $^{1 *}$, Harfia Mudahar ${ }^{2}$, Nurul Fazriyah ${ }^{3}$ \\ \{azrifitria@uinjkt.ac.id ${ }^{1}$,harfiamudahar@gmail.com², enjahelbantani@gmail.com ${ }^{3}$ \} \\ *corresponding author \\ Pharmacy Study Program, Faculty of Health Sciences UIN Syarif Hidayatullah Jakarta, Ciputat, 15419. \\ Indonesia ${ }^{1,3}$ \\ Department of pharmacy, Regional general hospital Cengkareng, West Jakarta ${ }^{2}$
}

\begin{abstract}
Appendicitis is the most common cause of acute abdomen which requires surgical treatment to prevent worse complications. Inappropriate use of prophylactic antibiotic is one of the triggers surgical site infection. This retrospective study aimed to determine the quantitative analysis of antibiotics prophylactic use according to the anatomical therapeutics chemical classification/defined daily dose (ATCC/DDD) methodology. This research was conducted using cross sectional design with retrospective data collection during January to December 2016 at regional general hospital in Jakarta and data were analyzed using the DDD method and drug utilization (DU) $90 \%$. A total of 119 total patients included as samples in this study. The results showed that the ceftriaxone was prophylactic antibiotic with highest DDD was $46.52 / 100$ patient-days. Prophylactic antibiotics included in DU 90\% segment were ceftriaxone and metronidazole. These study underline the need for antibiotic stewardship to improve the quality of antibiotic use.
\end{abstract}

Keywords: Prophylactic antibiotic, appendectomy, ATCC/DDD

\section{Introduction}

Antibiotic Prophylaxis is defined as the administration of antibiotics before, during, and maximum of 24 hours postoperative in cases that clinically do not show any infection symptoms in order to prevent surgical site infection [1]. Surgical site infections (SSI) is infection that occurs within 30 days after surgery. It remains a major cause of postoperative morbidity and mortality, prolong hospitalization and cost increase of medical care in the surgical unit [2].

One of the surgeries that highly recommended to administration prophylactic antibiotics is the removal appendix in acute appendicitis patients or known as appendectomy[3]. Appendicitis is an inflammation appendix that occurs as a result of luminal obstruction by polymicrobial infection [4]. Appendicitis was included in the top 10 diseases of Indonesia hospitalized patients in 2009, with the total number of cases was 30,703 and the mortality rate was 234 patients [5].

The high mortality rate of appendicitis patients is related to the presence of surgical site infection (SSI) post appendectomy. The incidence of surgical site infection in appendectomy patient has been reported in Korea (4.6\%), Brazil (7.2\%), China (6.2\%) and Sweden (5.9\%) [6]. One of the factors that can increase the high incidence of the SSI rate is the irrational use of prophylactic antibiotics, including the choice of antibiotics that is not based on local conditions or common pathogens in disease and the 
susceptibility of antibiotic, timing of administration, dosage of antibiotic, duration of antibiotic used and route of administration [3].

Based on the results of discussions with pharmacists at the Regional General Hospital in Jakarta hospital where the research was conducted that there are around 180 appendectomy patients every year. The hospital had been an interesting focus to identify a prophylactic antibiotics for appendectomy patients in order to analysis the actual of the antibiotic consumption. The irrational use of prophylactic antibiotics can allow surgical site infection incidence which is the main cause of increased morbidity and mortality after surgery, prolonging length of stay of patient and increasing hospital expenses especially in the field of surgical services [7]. The use of antibiotics needs to be minimized because it is known that overuse of antibiotics can increase the occurrence of resistance in the community so that becomes a focus both nationally and globally.

Analysis of drug use in units of quantity can help identify overuse and underuse in self-medication and groups. Drug use can be compared over time to monitor goals and to ensure that the medical therapy committee intervenes in increasing drug use [8]. Anatomical Therapeutic Chemical / Defined Daily Doses (ATC/DDD) as international standard system that recommended by WHO to serve as a tool for drug utilization monitoring and research in order to improve quality of drug use which can be compared with the amount of antibiotics used by departments or hospitals between countries ${ }^{[8]}$. This method will be used to evaluate drug use and detect early for irrational drug use [8]. Calculation of the amount of antibiotic consumption using the ATC / DDD analysis method is very important in terms of achieving a standard rate of antibiotic consumption at national and international hospitals. By comparing the total DDD antibiotic from each hospital, it will be known the level of antibiotic use in that hospital. In addition, by knowing the amount of DDD from each antibiotic, we will get the type of antibiotic that is often used so that it can be compared with the guideline.

The Drug Utilization 90\% (DU 90\%) is an indicator that shows the grouping of drugs into the $90 \%$ segment of use in DDDs. It is simple indicators reflecting the quality of prescribing or drug use. Assessment of drugs that are included in the $90 \%$ segment is needed to emphasize in the terms of evaluation, controlling and procurement planning drugs[9],[10],[11].

\section{Method}

This study was cross-sectional study conducted retrospectively by collecting medical records of appendicitis patients of the Regional Hospital, Jakarta, Indonesia between January to December 2016.

Inclusion criteria in this study were (i) appendicitis patients with aged $\geq 18$ years and undergoing appendectomy procedures, (ii) they have received prophylactic antibiotic before surgery, (iii) the complete and legible medical records. The exclusion criteria were appendicitis patients who did not meet the inclusion criteria.

Anatomical Therapeutic Chemical (ATC) with the Defined Daily Dose (DDD) unit as a global standard for the study of drug use and reporting of drug effect reactions. The ATC classification system is based on the anatomical, therapeutic, pharmacological and chemical subgroup[8]. ATC codes can be found in www.whocc.no/atc ddd index.

The data obtained were processed using the DDD method for quantity assessment. The DDD unit can be used to compare the use of different drugs in one therapy similarity, which have the same efficacy but differ in the dosage requirement. The calculation of DDD can be compared over time to monitor purposes and for guarantee of the intervention of the medical therapy committee in increasing drug use. ATC classification and DDD method are commonly used to compare usage consumption between countries. When applied in a hospital setting, the calculation of DDD / 100 patient-days or DDD / 100 bed-days is the most recommended [12].

The DDD is assumed average maintenance dose per day of drug used for its main indication in 
adults. The DDD value in grams of every drug is defined by the WHO standard. DDD values of every antibiotic is calculated separately. The $\mathrm{DDD} / 100$ patients days obtained by dividing the total drug use in the study period (in DDD units) by the total days of length of stay patient per 100. The segment for most commonly used antibiotic was determined based on DU $90 \%$ method by sorting the percentage use from the largest to the smallest, which then took the $90 \%$ largest segment of use [12].

The study has approval from the hospital management with number 851/-084.2/2017 and applies Indonesian law for the protection of personal data and the declaration of Helsinki.

\section{Results}

The characteristics of 119 patients enrolled in this study, it shows that patients woman are greater than men, consisted of women $(64.7 \%)$ and men $(35.3 \%)$. Patient age classification is divided into 4 categories, namely (18-30 years), (31-45 years), (46-60 years) and (61-75 years). Based on the age category, it can be seen that the age range 18-30 years is the age range for the most appendicitis patients found, namely 63 patients (51.5\%). The highest type of appendicitis is acute appendicitis (52.9\%). The characteristics of appendectomy patients who receive prophylactic antibiotics can be seen in table 1 .

Table 1. Data on Appendectomy Patient

\begin{tabular}{lcc}
\hline Characteristics & Number of Patient & Percentage (\%) \\
\hline Gender & 42 & \\
Men & 77 & 35.3 \\
Women & & 64.7 \\
Age Range & 63 & 52.9 \\
18-30 years & 31 & 26.1 \\
31-45 years & 18 & 15.1 \\
46-60 years & 7 & 5.9 \\
61-75 years & & \\
Type of Appendicitis & 63 & 52.9 \\
Acute Appendicitis & 9 & 7.6 \\
Perforated Appendicitis & 47 & 39.5 \\
Chronic Appendicitis & & \\
\hline
\end{tabular}

The length of stay patient ranged between 2- 15 days with average of 4.23 days. Based on the results, the highest percentage of appendectomy patients was treated for $2-3$ days $(45.8 \%)$.

Table 2. Length of Stay Appendectomy Patient

\begin{tabular}{ccc}
\multicolumn{3}{c}{ Table 2. Length of Stay Appendectomy Patient } \\
\hline Length Of Stay & Number of Patient & Percentage (\%) \\
\hline 2-3 days & 54 & 45.8 \\
4-5 days & 47 & 39.50 \\
6-7 days & 11 & 9.24 \\
$\geq 8$ days & 7 & 5.88 \\
\hline
\end{tabular}

Based on calculations using the ATC / DDD method, the third generation cephalosporins (ceftriaxone) was prescribed most frequently $(81.6 \%)$ as antibiotic prophylaxis in appendectomy patient, followed by metronidazole and cefoperazon sulbactam. 
Table 3. The Quantity of Antibiotic Used with DDD/100 patient days

\begin{tabular}{|c|c|c|c|c|c|c|}
\hline Antibiotic type & ATC code & $\Sigma$ Dosage (g) & DDD & $\begin{array}{l}\mathrm{DDD} / 100 \\
\text { days }\end{array}$ & $\%$ & Segment \\
\hline Ceftriaxone & J01DD04 & 468 & 234 & 46,52 & 81,60 & \multirow{2}{*}{$90 \%$} \\
\hline Metronidazole & J01XD01 & 42 & 28 & 5,57 & 9,76 & \\
\hline Cefoperazon Sulbactam & J01DD62 & 32 & 8 & 1,59 & 2,79 & \multirow{5}{*}{$10 \%$} \\
\hline Amikacin & J01GB06 & 8 & 8 & 1,59 & 2,79 & \\
\hline Cefotaxime & J01DD01 & 18 & 4.5 & 0,89 & 1,57 & \\
\hline Cefoperazon & J01DD12 & 17 & 4.25 & 0,84 & 1,48 & \\
\hline Total & & 585 & 286,75 & $\mathbf{5 7}$ & & \\
\hline
\end{tabular}

\section{Discussion}

Data on patient characteristics obtained included gender, age, type of appendicitis. Gender data shows that the dominance of appendicitis patients in Regional Hospital Jakarta was women with an incidence of 77 patients $(64.7 \%)$ while men were 42 patients $(35.3 \%)$. The result of this study is different from studies conducted by other studied who reported that appendicitis was more common in men than in women[13],[14]. The proportion of lymphoid tissue in men is more than in women, with these findings that can explain the incidence of appendicitis in men more than in women. Men are at twice the risk of suffering from appendicitis compared to women [15]. This difference was possible because of the limited number of patients compared to other studies.

The Patient age data shows that the highest patient age group was $18-30$ years with $52.9 \%$ with the highest number of patients at 19 years old. According to several studies the incidence of appendicitis often occurs in the young age group which is 15-30 years [13],[14],[16],[17]. This is in accordance with the majority of appendicitis patients in this study. Along the appendix tissue, there are lymphoid which is much larger in number in young subjects. Lymphoid hyperplasia is caused by damage to the lumen of the appendix which can develop into appendicitis. Therefore appendicitis is more common at a young age [15]. The number of appendicitis patients decreases with increasing age. So that in various studies found only $5-10 \%$ of cases of appendicitis in the old age [18].

The data on the length of stay are required to determine DDD units/ 100 patient-days in the use of prophylactic antibiotics appendectomy patients. LOS (length of stay) is the duration of hospitalization from the time the patients admission until the discharge from the hospital. Out of 119 patients, the length of stay ranged from 2-15 days with a total of 503 days and a mean of 4.2 days. According to several studies, the length of stay appendicitis patients depends on the complications presence such as perforation, comorbidities, the hospitals ability to control nosocomial infections, age, and nutritional status [19]. The results of the average length of stay in this study fall upon the standard range of length of stay in patients with acute appendicitis without complications with conventional appendectomy methods ranging from 3.5 to 4.5 days [19],[20]. As for this study, the length of stay of patients in the category of 6-7 days and $\geq 8$ days was owing to the patients undergoing perforated/abscess/infiltrates appendicitis, besides that the presence of comorbidities was also an issue that made prolonged the patients length of stay.

Quantitative antibiotic usage was measured by calculating DDD (Defined Daily Doses) per 100 patient days suggested by WHO. Using the DDD system calculation/100 patient-days can expected that the prophylactic antibiotics usage for appendectomy patients in certain installations or wards can be compared with other installations, even between hospitals or countries so as to improve the quality of prophylactic antibiotic usage. In this study, there were 6 variations in prophylactic antibiotics usage in appendectomy patients at Regional Hospital Jakarta. The total DDD / 100 patient-days value of each prophylactic antibiotic for appendectomy patients at Regional Hospital General Jakarta in 2016 was 
higher (57 DDD/100 patient-days) than the results of the study in one of Bandung Hospital especially prophylaxis antibiotic use in surgical digestive room (17,9 DDD/100 patient-days) ${ }^{[21]}$. Based on this result, there is a need for future studies regarding the high value of total DDD / 100-patient-days in this study, possibly due to overuse in terms of duration, timing or dosage of prophylactic antibiotics using for appendectomy patients in Regional Hospital General Jakarta.

The total calculation of DDD was $57 \mathrm{DDD} / 100$ patient-days can be concluded that among the 100 patients who were hospitalized, 57 patients received 1 DDD from the antibiotic class. The largest antibiotics usage was third-generation cephalosporin (ceftriaxone) at $46.52 \mathrm{DDD} / 100$ patient-days, followed by metronidazole at $5.57 \mathrm{DDD} / 100$ patient-days. This is in line with a study conducted by Guanche in 2016 which reported that the highest quantity of prophylactic antibiotic use in appendectomy patients was third-generation cephalosporin group, that was cefuroxime (233.3 $\mathrm{DDD} / 100$ procedures) and ceftriaxone $\left(67.1 \mathrm{DDD} / 100\right.$ procedures) ${ }^{[6]}$. Based on international guideline for prophylactic antibiotics in patients with acute appendicitis without complications, the recommended single dose of cephalosporin generation II (cefoxitin, cefotetan) or a combination generation I of cephalosporin with the imidazole class (cefazolin + metronidazole) ${ }^{[22]}$. However, the choice of prophylactic antibiotics should also be based on local resistance patterns, the availability of antibiotics, and the spectrum of microbial pathogens in hospitals.

Prophylactic antibiotics that entered the $90 \%$ DU segment consisted of the cephalosporin group (ceftriaxone $81.6 \%$ ) and the imidazole group (9.76\% metronidazole). While those included in the $10 \%$ DU segment were cefoperazone-sulbactam $(2.79 \%)$, amikacin $(2.79 \%)$, cefotaxime $(1.57 \%)$ and cefoperazone $(1.48 \%)$. The results of this study are in line with research conducted by Guanche et al (2016) which showed that $90 \%$ of the prophylactic antibiotics used in appendectomy patients at a hospital in Qatar for the period 2013-2015 were cefuroxime, metronidazole and ceftriaxone [6].

Measurement of antibiotic consumption is highly recommended to measure adherence to antibiotic use based on national or international guidelines. The main objective of this program is to reach optimal clinical outcomes, and lower the toxic level exposures. In addition, a reduction in the level of overconsumption of prophylactic antibiotics will be in line with hospital cost reduction, an increase in the timeliness and duration of antibiotic administration. Also, an important goal is addressed to limit the antibiotic resistance. An important added benefit is the reduction of consumption related overuse of antibiotics and consequently, the reduction of cost [23]

This study has some limitation of the data obtained from the patient's medical records. The research is retrospective, so the author cannot see the actual condition of the patient and cannot confirm prophylactic antibiotic regimens received by the prescribers because the decision to treat acute uncomplicated appendicitis patients with antibiotics must be made on an individual basis.

\section{Conclusion}

The total DDD/100 patient-days value of each prophylactic antibiotic for appendectomy patients at Regional Hospital General Jakarta in 2016 was 57 DDD/100 patient-days. These study showed that the ceftriaxone was prophylactic antibiotic with highest DDD was $46.52 / 100$ patient-days. Prophylactic antibiotics included in DU 90\% segment were ceftriaxone and metronidazole. The total DDD / 100 patient-days value of this study was higher than other study that related. The future study about the quality of appropriate prophylactic antibiotic use in appendectomy patients is recommended.

\section{References}

[1] Indonesian minister of health (2015), Program Pengendalian Resistensi Antimikroba di Rumah Sakit. Hukor 
Depkes RI, 23-24

[2] Ducel et al. (2002). Prevention of hospital-acquired infections World Health Organization.

[3] SIGN, S. I. G. N. (2014). SIGN 104 - Antibiotic prophylaxis in surgery. NHS - SIGN Clinical Guideline, 104(April), 1-67.

[4] Bennet, J.E., Dolin, R. dan Blaser, M.J., (2014). Mandell, Douglas, and Bennett's Principles and Practice of Infections (Larchmt)., 13(4), 234-7.

[5] Indonesian Minister of Health (2010). Profil Kesehatan Indonesia Tahun 2009.

[6] Guanche Garcell, H., Villanueva Arias, A., Pancorbo Sandoval, C. A., Valle Gamboa, M. E., Bode Sado, A., Alfonso Serrano, R. N., \& Guilarte García, E. (2017). Incidence and Etiology of Surgical Site Infections in Appendectomies: A 3-Year Prospective Study. Oman Medical Journal, 32(1), 31-35.

[7] Radji, maksum et al (2014). of antibiotic prophylaxis administration at the orthopedic surgery clinic of tertiary hospital in J akarta , I ndonesia, 4(3), 190-193.

[8] WHO. (2015). Guidelines for ATC Classification and DDD assignment.

[9] Goossens H, Ferech M, Vander SR, Elsevier M. Outpatient antibiotic use in Europe and association with resistance: a cross-national database study. The lancet. 2005

[10] Sketris IS, Metge CJ, Ross JL, MacCara ME, Comeau DG, Kephart GC, et al. The use of the world health organization anatomical therapeutic chemical/defined daily dose methodology in Canada. Drug Inf J. 2004.

[11] De WK, Bestehorn H, Steib-Bauert M, Kern WV. Comparison of defined versus recommended versus prescribed daily doses for measuring hospital antibiotic consumption. Infection. 2009.

[12] WHO. (2003). Introduction to Drug Utilization Research Introduction to Drug Utilization Research. Introduction to Drug Utilization Research.

[13] Sulu, B. (2012). Demographic and Epidemiologic Features of Acute Appendicitis. Appendicitis - A Collection of Essays from Around the World, 169-179.

[14] Bohrod, M. G. (1946). The pathogenesis of acute appendicitis, 752-760.

[15] LEE JA. The influence of sex and age on appendicitis in children and young adults. Gut. 1962;3(1):80-84. doi:10.1136/gut.3.1.80

[16] Humes, D. J., \& Simpson, J. (2006). Clinical review Acute appendicitis, 333(September), 530-534.

[17] Petroianu, A., Vinicius, T., \& Barroso, V. (2016). Pathophysiology of Acute Appendicitis, 4, 4-7.

[18] Omari AH, Khammash MR, Qasaimeh GR, Shammari AK, Yaseen MK, Hammori SK. Acute appendicitis in the elderly: risk factors for perforation. World J Emerg Surg. 2014;9(1):6. Published 2014 Jan 15. doi:10.1186/1749-7922-9-6

[19] Mansur, M., \& S, M. A. (2013). Analisis Variasi Pengelolaan Appendicitis Akut di Rumah Sakit Wava Husada Malang Variation Analysis of Appendicitis Acute Management in Wava Husada Hospital, 28(1), $109-113$.

[20] Karatparambil, A., Kummankandath, S. A., Mannarakkal, R., Nalakath, M. R., \& Babu, D. (2016). Laparoscopic versus open appendicectomy: a comparative study, 3(1), 128-134..

[21] Mahmudah, febrina et al (2014) Study of the Use of Antibiotics with ATC/DDD System and DU 90\% in Digestive Surgery in Hospital in Bandung, DOI: 10.15416/ijcp.2016.5.4.293

[22] Ashp, \& BHH. (2013.). Clinical Practice Guidelines for Antimicrobial Prophylaxis in Surgery Guidelines Development and Use, 195-222.1

[23] Humberto G. Garcell, Ariadna V. Arias, Cristobal P. Sandoval, Moraima E. Valle Gamboa, Adan B. Sado, Ramon N. Alfonso Serrano, Impact of a focused antimicrobial stewardship program in adherence to antibiotic prophylaxis and antimicrobial consumption in appendectomies, Journal of Infection and Public Health, Volume 10, Issue 4,2017, Pages 415-420, 